Original Research Paper

\title{
A Simulation Study of Enhanced Distillation Using Ultrasound Waves for the Separation of Azeotropic Mixtures
}

\author{
${ }^{1,2}$ Taha Mahdi and ${ }^{3}$ Ammar Emad Al-Kawaz \\ ${ }^{1}$ Midland Refineries Company, Ministry of Oil, Daura, Baghdad, Iraq \\ ${ }^{2}$ Chemical Engineering, University of Babylon, Iraq \\ ${ }^{3}$ Polymer and Petrochemical Industry, College of Material, University of Babylon, Iraq
}

Article history

Received: 7-12-2017

Revised: $20-12-2017$

Accepted: $27-12-2017$

Corresponding Author:

Taha Mahdi

Chemical Engineering,

University of Babylon,

Babylon, Iraq

Email: tahamahdi9@gmail.com

\begin{abstract}
The potential of ultrasound waves to enhance distillation system for azeotropic mixture is examined through process flowsheeting using Aspen Plus. Since sonication is not a standard feature in the software library, a mathematical model of the proposed distillation system is developed based on first principles in Aspen Custom Modeler and later exported to Aspen Plus environment for process simulation and design studies. Ethyl acetate and ethanol mixture is used as a case study, with a target of producing $99 \%$ pure top product from a feed containing $65 \%$ ethyl acetate. Sensitivity analyses are carried out to examine the influence of various design and operating variables of the top product's purity and heat duties. When compared to extractive distillation, the proposed ultrasonic distillation process offers a $14.6 \%$ savings of operation costs. The proposed distillation system has also been tested for other azeotropic mixtures with similar success.
\end{abstract}

Keywords: Process Intensification, Sonication, Azeotropic Mixture, Aspen Custom Modeler, Aspen Plus

\section{Introduction}

Separation of azeotropic mixtures is known to be challenging and many alternatives have been introduced including conventional and emerging processes such as extractive distillation azeotropic distillation, pressure swing distillation, pervaporation and dividing-wall distillation column (Mahdi et al., 2015a; Alkhudhiri et al., 2012; Liang et al., 2017). While some of these processes have been in commercial use, there is a need to develop new processes with more attractive capital and operating cost requirements since distillation is widely used in the process industry and consuming large amount of energy. One way of realizing this is by exploiting some peculiar physical and chemical phenomena within existing processes to provide higher efficiency and equipment size reduction. This sets the premise for the development of emerging processes under the theme of process intensification.

One way of applying this approach is to exploit sonochemistry in enhancing the process performance. In addition to the widespread application of ultrasound in facilitating cleaning processes, its application can also be found in reaction systems such as biodiesel production
(Chen et al., 2014), ethanol fermentation (Sulaiman et al., 2011) and separation system such as adsorption (Bono et al., 2008). Its application to distillation process is however still limited. Nii et al. (2006) have examined the use of ultrasonic atomizer to disperse ethanol solution into air streams and concluded that better energy saving processes can be established compared to normal distillation. In another perspective, sonication has also been shown to positively impact the Vapor-Liquid Equilibrium (VLE) of azeotropic mixtures (Ripin et al., 2009). Similar trends are also obtained on other compounds including ethanol-ethyl acetate mixture (Mahdi et al., 2014). Inspired by these results, a mathematical model of a single stage VLE system has been derived and validated (Mahdi et al., 2015b) and based on this model, the design of an ultrasonically intensified distillation system based is proposed and elaborated in this study.

\section{Mechanism of Ultrasonic Separation}

Acoustic cavitation is a phenomenon by which ultrasonic waves induce bubbles formation, growth and collapse (Apfel, 1997). The collapse normally takes 
place when the bubble reaches critical size referred to as the resonance size. Depending on the operating condition, the growth-collapse process may end up in two possible scenarios. Firstly, if they are smaller than the resonance size, bubbles tend to migrate from the minimum pressure, also known as pressure node to the maximum pressure referred to as antinode. This is driven by primary Bjerknes forces and will lead to a condition whereby bubbles are collapsing inside the liquid and generating high temperature (Ashokkumar et al., 2007). This causes the formation of radicals and highly reactive intermediates within the bubbles during the collapse. For this reason, they are called "active" cavitation bubbles. This condition facilitates various chemical pathways, thus enhancing sonochemical reactions (Ashokkumar and Mason, 2007). Recently, numerous papers have reported enhancement effect of ultrasound on biodiesel synthesis with basic strength of catalyst (Parkar et al., 2012; Choudhury et al., 2014). They established the mechanism of this enhancement by discrimination of the physical and chemical effects of cavitation bubbles in the system on transesterification of oil with alcohol using a catalyst.

Secondly, if they are larger than the resonance size, they will be forced to the node to become "inactive". These bubbles eventually float out of the liquid due to buoyancy forces and collapse at the liquid surface (Louisnard and González-García, 2011). Similar observation is reported in a study involving ethanol/water mixture, where the bubble travel through the liquid mixture and collapse in the fountain jet formed at the liquid surface releasing the alcohol vapor in the bubble (Suzuki et al., 2012). These phenomena have significant impact on mechanical and physical processes such as cleaning and vapor-liquid separation processes

Based on the above arguments, the system is considered "inactive" at low frequency, high temperature and hydrocarbons are involved (Mahdi et al., $2015 b)$. It is also important to note that the ultrasonic wave generates micro-point vacuum condition within the liquid during bubbles formation. In this condition, azeotrope of the vapor components inside the bubbles is altered, resulting in changes in vapor liquid equilibrium. This is confirmed by a various studies that proved the breaking of azeotrope under vacuum pressure condition (Kamihara et al., 2008; Wisniak et al., 2001). To understanding the mechanism of the enhancement separation of the system in this process, these bubbles eventually float out of the liquid due to buoyancy forces and collapse at the liquid surface in the fountain jet releasing the vapor in the bubble to the vapor phase. Thus, the mole fractions of the vapor inside the bubbles are considering equal to those in the vapor phase. These are the scenarios considered in this study.

\section{Mathematical Modeling}

The schematic diagram of the distillation system is shown in Fig. 1. Using conservation principles and thermodynamic equilibrium as the central principles, a mathematical model of the system is derived. In this process, a feed with a molar flow rate $F$ and composition $\mathrm{xf}$ is separated into a lighter top product $\mathrm{D}$ and a heavier bottom product $\mathrm{B}$ with compositions $\mathrm{xd}$ and $\mathrm{xb}$, respectively. Sonication is introduced at each separation stage and each separation stage is assumed to be in phase equilibrium. The model follows a stage-to-stage calculation with a top-down numbering approach for the stages (i.e., the first stage is the condenser).

\section{Material and Energy Balances}

To illustrate the mathematical modeling for the material and energy balance of the column as shown in Fig. 1, the distillation column is separated into five parts that are explained in the following subsections: Condenser, reboiler, feed stage, rectifying and stripping.

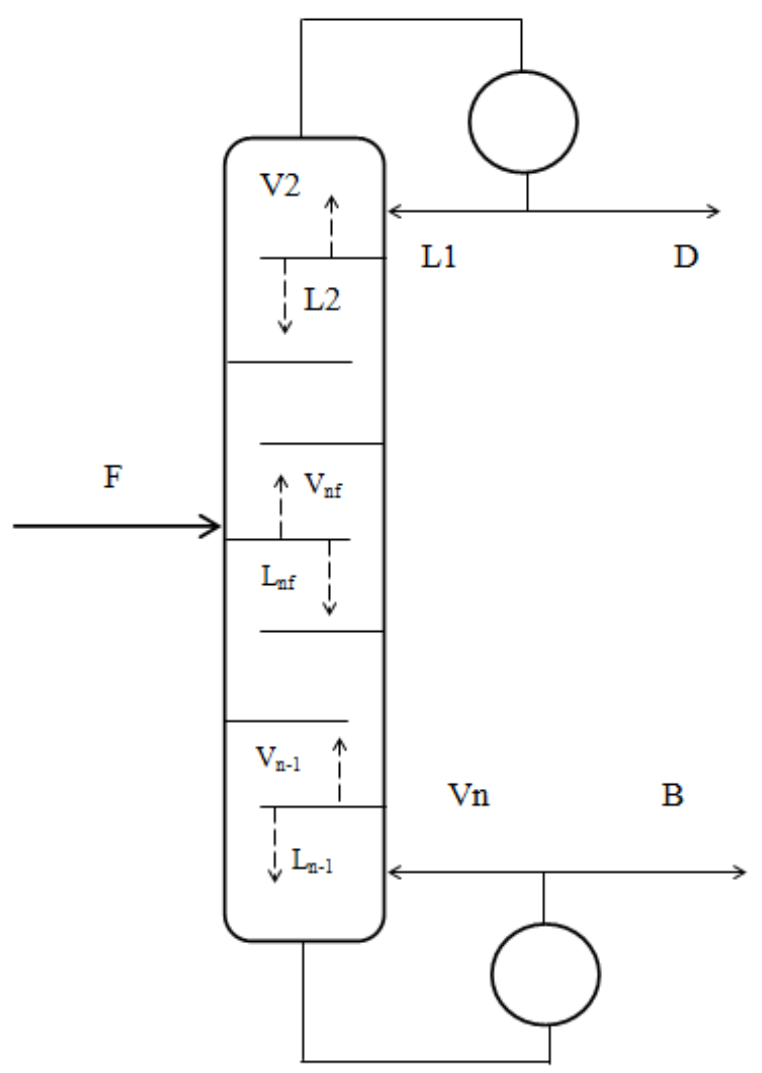

Fig. 1: Schematic diagram of the ultrasonic distillation process 


\section{Maintaining the Integrity of the Specifications}

The template is used to format your paper and style the text. All margins, column widths, line spaces and text fonts are prescribed; please do not alter them. Your paper is one part of the entire proceedings, not an independent document. Please do not revise any of the current designations.

\section{Condenser, Reboiler and Feed Stage}

The condenser accepts the vapor rising from the top stage and removes a significant amount of heat to produce liquid that is collected in the distillate drum. In this study, total condensation is assumed. For this subsystem, the overall material and heat balance equations are similar manner to a condenser, reboiler and Feed Stage of ordinary distillation column.

\section{Rectifying and Stripping Stages}

Apart from the specified feed stage, condenser and reboiler, all other stages can be represented by generic balance equations for the $i$ th stage. A mathematical model of total material and component balance for the ultrasonic distillation is essentially similar to ordinary distillation column. In the rectifying section, ultrasonic waves are introduced to the liquid accumulated on the tray. The energy balance equation can be written as follows:

$$
L_{i-1} * h_{L(i-1)}+V_{i+1} * h_{V(i+1)}=L_{i} * h_{L i}+V_{i} * h_{V i}+q_{U}
$$

Here, $i+1$ refers to the stage below the $i$ th stage, $i-1$ refers to the stage above the $i$ th stage, $h_{v}$ and $h_{L}$ are enthalpies of the vapor and liquid phases, respectively and $q_{U}$ is the ultrasonic energy that is provided to the stage by a transducer. It is represented by the ratio of ultrasound intensity $(I)$ to the sound of speed in a liquid medium $(c)$, as shown in Equation 2:

$q_{U}=\frac{I}{c}$

The striping section has the design of an ordinary distillation column and the energy balance equation can be represented by:

$$
L_{i-1} * h_{L(i-1)}+V_{i+1} * h_{V(i+1)}=L_{i} * h_{L i}+V_{i} * h_{V i}
$$

\section{Thermodynamic Equilibrium}

Sonication is a fast process with intermittent spikes of energy appearing on the order of microseconds. It also produces ultrasonic waves that generate micro-point vacuum conditions within the liquid during bubble formation. Because these phenomena happen very fast, the net temperature changes to the bulk liquid are minimal. It is therefore reasonable to assume that vapor-liquid equilibrium can take place in a similar manner to normal separation processes. Treating the components in the liquid phase as a non-ideal mixture and the components in the vapor phase are treated as an ideal mixture with a fugacity coefficient equal to unity. The resulting equilibrium relationship yields the modified Raoult's law:

$P^{*} y_{i}=\gamma_{i}^{*} p_{i}^{\circ * x_{i}}$

\section{Sonochemistry}

The central theme of this innovation is based on the proposition that the rapid phenomena of generation, expansion, compression and collapse of micro-bubbles as a result of sonication alter the thermodynamic property of the liquid to the extent that it positively shifted the azeotrope point. At the limit, an azeotrope is eliminated and high purity separation is made possible via distillation. It is also assumed that the equilibrium takes place when the bubble is at its maximum size prior to collapse. By calculating the molar composition of the vapor components inside the bubble $y_{i}$ at this condition and with the physical properties of the liquid, the liquid composition can be computed using Equation 4, thus defining the VLE conditions. Details of this model are explained elsewhere (Mahdi et al., 2015b) and only a summary is provided here.

The molar composition in the vapor phase is computed based on the condition at the maximum bubble size prior to collapse, at bubble radius $R_{\max }$. The molar composition of component $i$ is given by:

$y_{i}=\frac{n_{i}}{N}$

Here, $n_{i}$ is the total number of component $i$ and $N$ is the total number of all components inside the bubble. The number of moles of component $i$ can be estimated from the ideal gas relationships as follows:

$n_{i}=\frac{4 \pi P_{i} R_{\max }^{3}}{3 \Re T}$

Here, $P_{i}$ is the partial pressure of component $i, T$ is the temperature inside the bubble, $\mathfrak{R}$ is the ideal gas constant and $R_{\max }$ is the maximum bubble radius that can be determined from the Rayleigh-Plesset equation and is influenced by the ultrasonic frequency and intensity. 


\section{Ultrasonic Distillation Design}

\section{Case Study: Ethanol-Ethyl Acetate}

As a case study, Ethanol/Ethyl Acetate (ETOH/ETAC) separation process is chosen. Ethyl Acetate (ETAC) is an important solvent that is used in a wide range of applications in the industry and is commonly produced by Esterification of ethanol (ETOH) with acetic acid. It is assumed that the feed to the proposed distillation system is supplied from a reactor in a typical ETAC manufacturing facility with a product composition containing $65 \%$ ETAC at $333.15 \mathrm{~K}$ and 1 bar $(20$. Unfortunately, a mixture of ETAC and ETOH is known to form an azeotrope at $55 \mathrm{~mole} \%$ of ETAC at a minimum boiling point of $71.8^{\circ} \mathrm{C}$, thus making the product purification process very challenging.

\section{Process Simulation}

The proposed distillation system, herein called Ultrasonic Distillation (UD), is similar to an ordinary distillation column except for the addition of an ultrasonic transducer in the equilibrium stages. For flexibility, the location of these stages depends on the feed composition because it is intended that the sonication stages start from the feed stage to the top column (rectifying section), while the stages of the striping section do not have a transducer. Simulation studies on the proposed design based on the mathematical model described above are carried out in an Aspen Custom Modeler (ACM) flowsheeting environment.

A fresh feed stream containing $65 \mathrm{~mol} \%$ ETAC and $35 \mathrm{~mol} \% \mathrm{ETOH}$ at a flow rate of $100 \mathrm{kmol} / \mathrm{h}$ is fed into the bottom of the column because it is above the azeotrope point of $0.55 \mathrm{~mol} \%$ ETAC. The operating conditions of the ultrasound transducer are based on the optimum operation conditions obtained from previous works 7,8 , which include the settings of $500 \mathrm{~W} / \mathrm{cm}^{2}$ ultrasound intensity and $25 \mathrm{kHz}$ frequency. The reflux ratio and number of stages used are 8 and 35, respectively. According to these operating conditions, the bottom composition is rich with ETOH, while the purity of products at the distillate stream contains 99 mol\% ETAC. The NRTL equation is used to compute the activity coefficients of the liquid phase because it is recommended for liquid-liquid systems containing an alcohol and nonpolar hydrocarbon liquids such as ETAC (Kirpalani and Toll, 2002). For the vapor phase, ideal gas behavior is assumed.

\section{Separation Potentials}

Sensitivity analyses are carried out to study the effect of the distillation design parameters on the quality of separation achieved. This is to verify the adequacy of the design parameters to establish the targeted separation quality.

\section{Effect of the Number of Theoretical Stages}

The number of theoretical stages sets the size of the column. More stages reflect a taller column and more opportunity for contacts between components, thus increasing the achievable separation. This is illustrated in Fig. 2 where the potentials plateaued when 35 trays are used. At this value, the targeted $99 \%$ ETAC purity in the distillate is achievable.

\section{Effect of Feed Stage Location}

Figure 3 highlights that a feed stage has linear effects on the achievable purity if the feed location is moved above stage 8 to about stage 13 before the sensitivity is reduced. The result also affirmed the choice of stage 17 as the feed location to provide the intended separation quality.

\section{Effect of Reflux Ratio}

The effect of the reflux ratio on ETAC composition is consistent with that of normal distillation. Figure 4 shows the upward trend of the distillate composition of ETAC with increasing reflux ratio. The desired purity of $99.0 \mathrm{~mol} \%$ ETAC is achieved when the reflux ratio is set to 8 . A rising reflux ratio increased the liquid flow in the column and resulted in more opportunity for contacts between vapor and liquid phases.

\section{Effect of Ultrasonic Intensity and Frequency}

A salient feature of the proposed ultrasonic distillation system is the use of ultrasonic transducers on the equilibrium stages of the rectifying sections, which adds two additional variables, namely ultrasonic intensity and frequency, to the process operations. Following a recommendation from the previous experimental work 9 with a frequency fixed at $25 \mathrm{kHz}$, the effect of ultrasonic intensity on ETAC purity is shown in Figure 5. It is noted that increasing the intensity provides a positive impact on the achievable product purity and a 99 mole\% ETAC in the distillate stream is established when the intensity is $500 \mathrm{~W} / \mathrm{cm}^{2}$. Above this value, the sensitivity significantly declines to finally reach a plateau.

As previously explained (Mahdi et al., 2015b), ultrasonic intensity impacts the process by varying the bubble populations in the liquid medium. By producing more micro-bubbles along with the associated vacuum effects inside the liquid, the thermodynamics of the system are impacted to the extent that it alters the VLE of the system (Katikaneni and Cheryan, 2002), thus making the separation easier. 


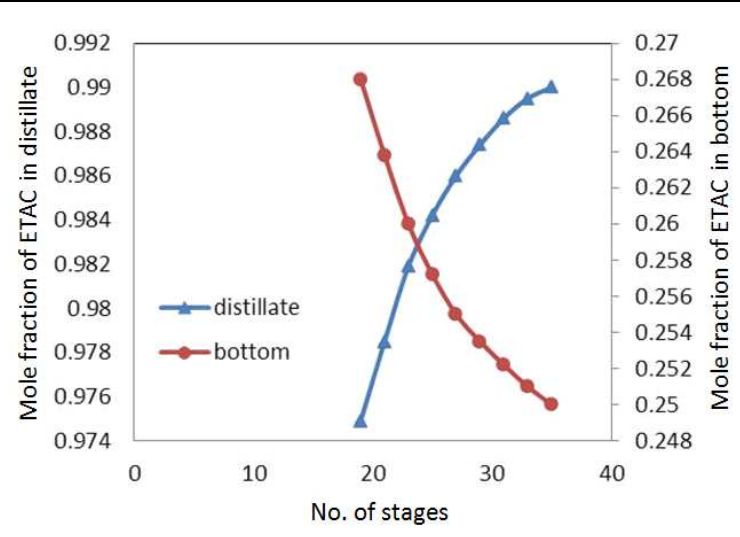

Fig. 2: Effect of the number of stages on ETAC purity in the distillate and bottom streams of the UD column

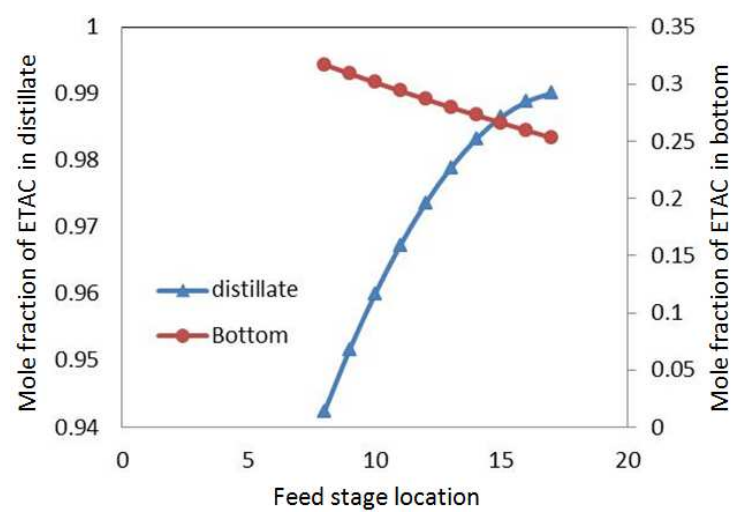

Fig. 3: Effect of feed stage location on ETAC purity in the distillate and bottom streams of the UD column

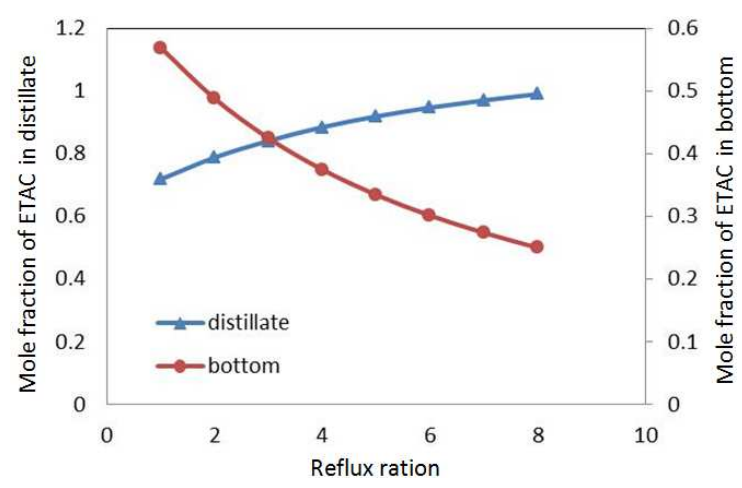

Fig. 4: Effect of reflux ratio on ETAC purity in the distillate of the UD column

The effect of the sonication frequency is shown in Fig. 6. Operating at a sonication intensity of $500 \mathrm{~W} / \mathrm{cm}^{2}$, an increase in frequency results in a negative effect in product purity. Note that the ultrasonic frequency affects the size of the bubbles formed; the bubble size increases with decreasing frequency. This facilitates mass transfer into the bubbles and their movements upward to collapse on the surface of the liquid, as desired by the vaporliquid separation process.

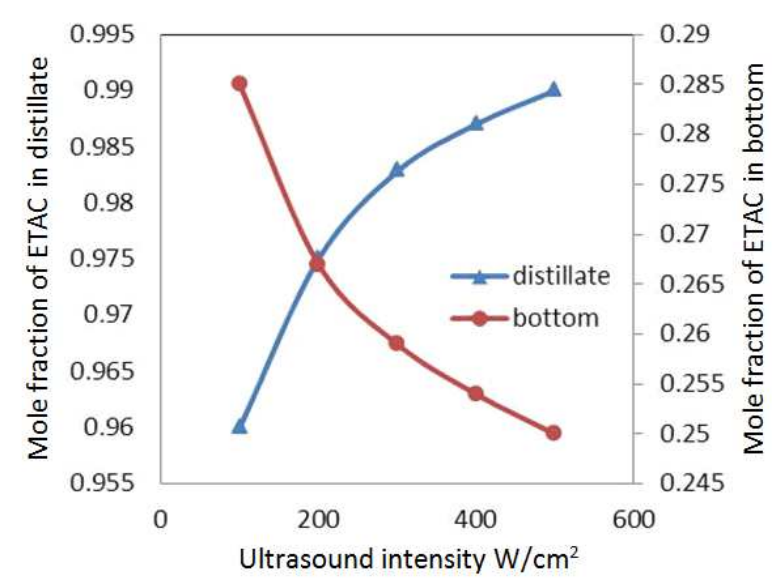

Fig. 5: Effect of ultrasonic intensity on ETAC purity in the distillate and bottom streams of the UD column

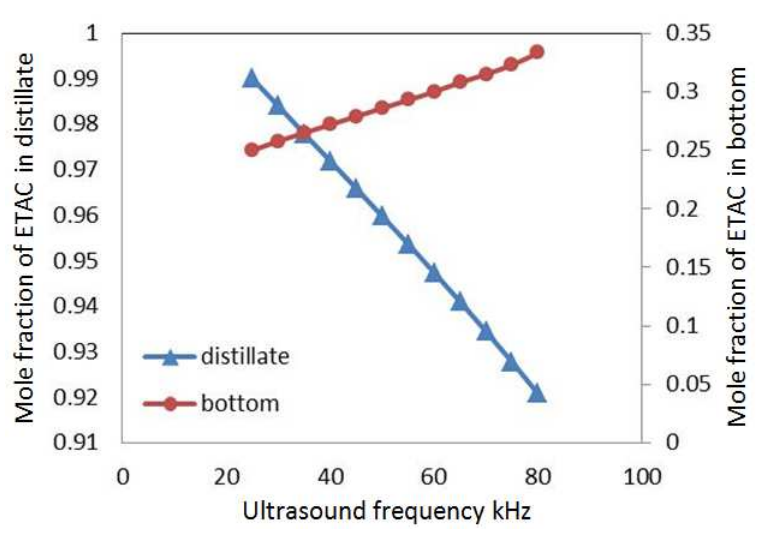

Fig. 6: Effect of ultrasound frequency on ETAC purity in the distillate of the UD column

\section{Energy Requirements}

The addition of an ultrasonic transducer provided advantages as previously discussed. It nevertheless adds an additional energy requirement, electricity. It is therefore important to observe the sensitivity of the proposed design on the overall heat duties of the system. There are three major components of heat duties in the operation of the proposed column, i.e., condenser $\left(Q_{C}\right)$, reboiler $\left(Q_{B}\right)$ and ultrasonic related energy $\left(q_{U}\right)$. The total ultrasonic energy, $Q_{U}$, is calculated by multiplying the energy requirement of each transducer given in Equation 7 with the number of transducers used in the system $\left(N_{\text {trans. }}\right)$ :

$Q_{U}=q_{U} * N_{\text {trans }}$

Because the design parameters such as feed location and the number of stages are fixed based on the purity requirement, the assessment discussed here focused only on key operating conditions. 


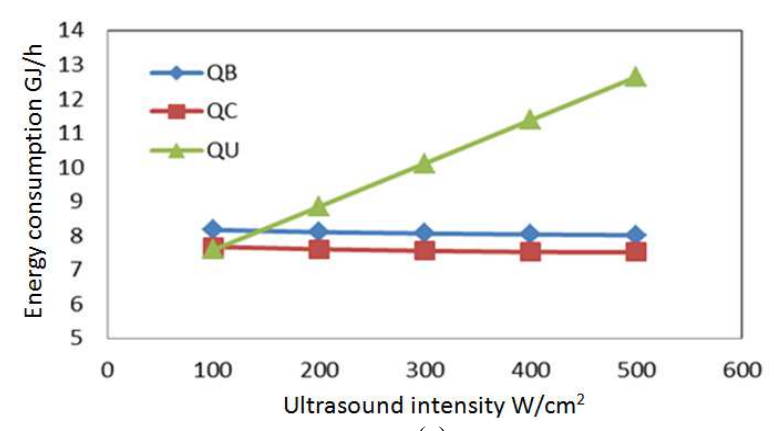

(a)

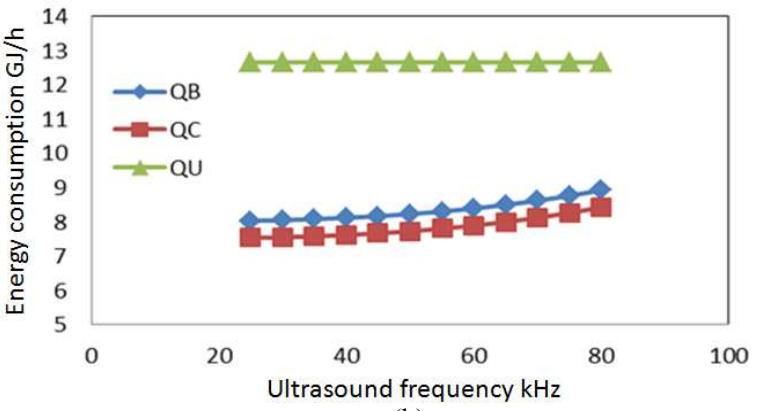

(b)

Fig. 7: Effect of ultrasonic intensity and frequency on condenser and reboiler heat duties of the UD column

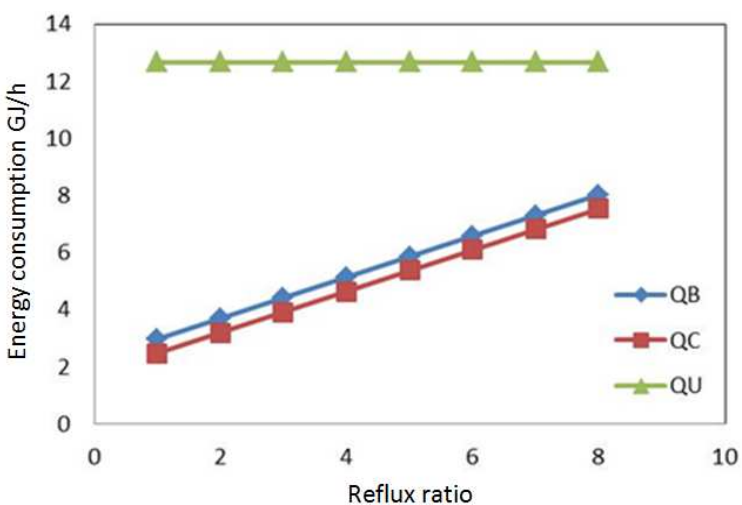

Fig. 8: Effect of reflux ratio on condenser and reboiler heat duties of the UD column

\section{Effect of Ultrasonic Intensity and Frequency}

Figure 7 shows that the condenser and reboiler duties are less sensitive to the changes in intensity and frequency. This is because the sonication phenomena have minimal impacts on the bulk temperature of a liquid medium (Merouan et al., 2013). The energy requirement to power the sonication device is also not affected by the frequency setting but is strongly influenced by the intensity. This is clearly shown in Fig. 7a, where increasing the operational frequency demands higher electrical energy.

\section{Effect of Reflux Ratio}

The reflux ratio has a similar influence on the QC and $\mathrm{QB}$ as in a normal distillation and is irrelevant to the QU. Increasing the reflux ratio introduces more liquid into the column, thus increasing the energy consumption of the condenser and reboiler heat duties as shown in Fig. 8.

\section{Optimal Design}

The sensitivity analyses provided the response of key performance characteristics towards the design specifications and operating conditions. Based on these insights, the column is optimized to determine the optimum settings based on six design variables, aiming at maximizing the ETAC purity in the distillate.
Table 1: Optimum design parameters at ETAC purity of 99.9 $\mathrm{mol} \%$ for the UD column

\begin{tabular}{lr}
\hline Parameters & Values \\
\hline No. of trays & 41.00 \\
Feed stage locations & 27.00 \\
Reflux ratio & 9.18 \\
Bottom flowrate kmol/hr & 42.23 \\
Intensity W/cm $^{2}$ & 617.00 \\
Frequency kHz & 21.40 \\
\hline
\end{tabular}

The variables are the ultrasound intensity and frequency, number of trays, feed stage locations, reflux ratio and bottom flow rate. This is carried out with fixed feed conditions (flow rate, temperature and compositions) and column pressure. The optimization is carried out using a successive quadratic programming algorithm, known as FeasOpt optimization method available as part of the ACM simulator library is used. Feasible Optimization (FeasOpt) is a feasible path successive quadratic programming optimizer. It can be used for optimization or maximum log likelihood estimation. FeasOpt evaluates the objective variable at the current point and moves the design variables, initial and control variables (in the case of optimization) or estimated variables (in the case of estimation) to take the objective variable towards its optimum value. After solving with the new values of the design, initial and control variables or estimated variables, FeasOpt re-evaluates the objective variable. In this way, FeasOpt steps towards the optimum solution, more details can be found in the Aspen Tech (Chang et al., 2012). The optimization results of the UD process are summarized in Table 1.

\section{Generalization of the Proposed Design}

Although the study focused on the ETAC/ETOH mixture, the proposed design can also be extended to other mixtures. As an illustration, a few selected azeotropic mixtures with different relative volatilities are 
examined. Azeotropes are formed at $89.4 \mathrm{~mol} \%$ ethanol at $78.1^{\circ} \mathrm{C}$ for an ethanol-water mixture, $76.5 \mathrm{~mole} \%$ of water at $92.4^{\circ} \mathrm{C}$ for an $\mathrm{n}$-butanol/water mixture and 66 mol\% methyl acetate at $53.5^{\circ} \mathrm{C}$ for a methyl acetate/methanol mixture.

\section{Simulation Conditions}

In all cases, the target product purity of $99 \mathrm{~mol} \%$ in the distillate stream is set. The design parameters for the distillation system to be used for the various mixtures are fixed using a typical distillation design procedure and operating parameters such as reflux ratio, number of theoretical trays, feed tray location and bottom flowrate feed ratio and other specifications are fixed as shown in Table 2. The results obtained proved the capability of the proposed UD process in providing the intended separations for all of the mixtures. The largest number of stages, 37, is needed for the ETAC/ETOH system, while the 20 stages required for the n-Butanol-water system is the lowest number of stages required. The difference in the number of sonication stages required for separating the binary azeotrope mixtures is influenced by the relative volatility of the systems, with the highest being the easiest.

The parameters of the sonication device are fixed at the preferred conditions with intensity at 500 $\mathrm{W} / \mathrm{cm}^{2}$ ultrasound and frequency at $25 \mathrm{kHz}$ and a total flow of $100 \mathrm{kmol} / \mathrm{h}$ of saturated liquid at $25^{\circ} \mathrm{C}$. Similarly, in all cases, an NRTL model is used for the liquid phase and ideal behavior is assumed for the vapor phase. For the purpose of comparison, feed compositions for all mixtures are fixed at $50 \mathrm{~mol} \%$ of the light component. Note that because the purpose of this study is to illustrate only the potential of the proposed designs to be generalized for other mixtures, optimum operating conditions for each pair have not been determined.

Figure 9 shows the shift of the azeotropic point with an increasing number of stages in the rectifying section of the UD column. The results indicate that the proposed UD system is capable of overcoming azeotropes in all mixtures considered. The number of stages required corresponds to their relative volatilities.

Table 2: Operation conditions of a UD column for separation of the systems

\begin{tabular}{|c|c|c|c|c|}
\hline $\begin{array}{l}\text { Specifications of } \\
\text { the UD column }\end{array}$ & $\begin{array}{l}\text { Ethanol }+ \\
\text { Ethyl Acetate }\end{array}$ & $\begin{array}{l}\text { Methyl acetate }+ \\
\text { Methanol }\end{array}$ & $\begin{array}{l}\text { Ethanol + } \\
\text { Water }\end{array}$ & $\begin{array}{l}\text { n-Butanol + } \\
\text { Water }\end{array}$ \\
\hline Average Relative Volatility & 1.15 & 1.6 & 2.9 & 3.1 \\
\hline Reflux ratio & 8.00 & 5.0 & 3.5 & 2.0 \\
\hline No. of Stages Required & 37.00 & 31.0 & 23.0 & 20.0 \\
\hline Feed tray location & 24.00 & 19.0 & 14.0 & 11.0 \\
\hline Bottom flow rate & 60.00 & 53.0 & 48.0 & 45.0 \\
\hline
\end{tabular}

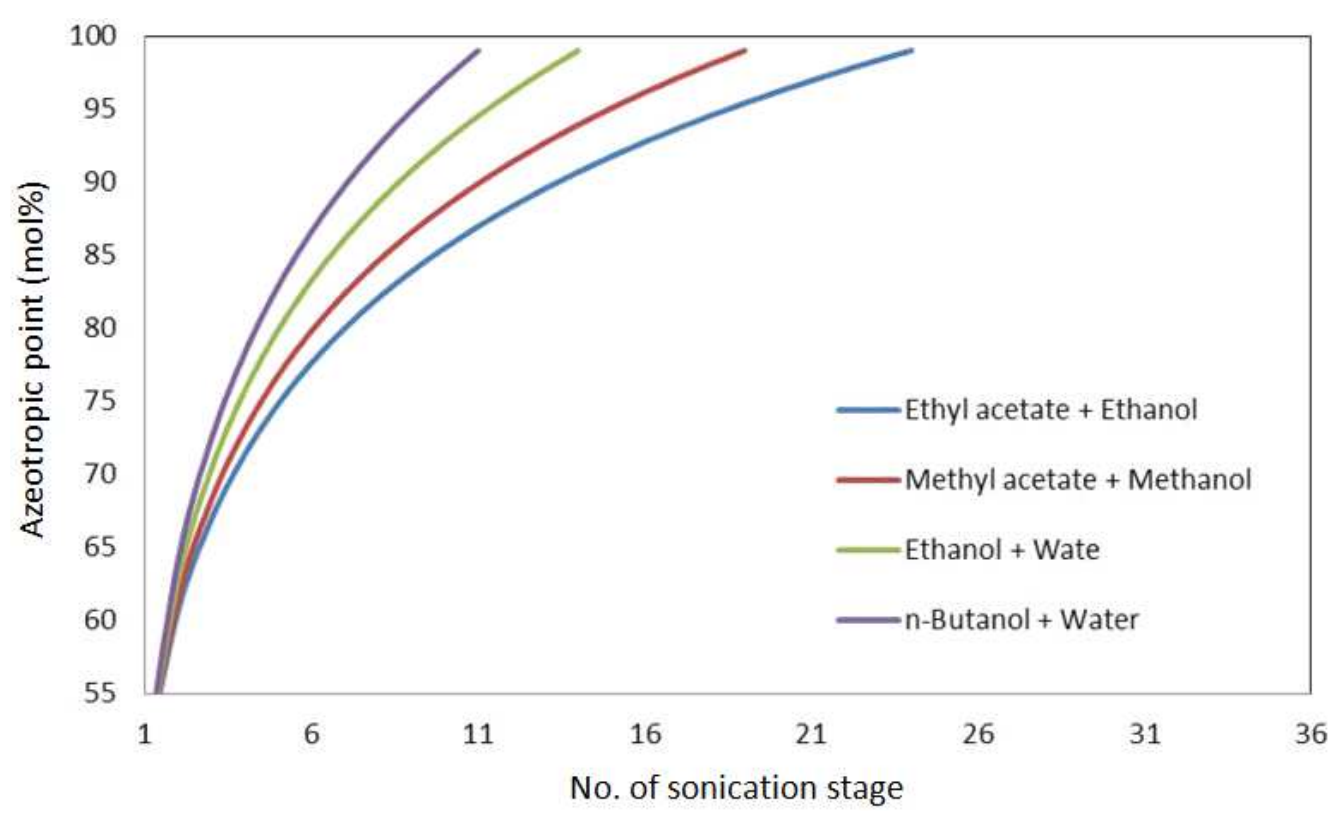

Fig. 9: Azeotropic point of a mixture related with number of sonication stages 


\section{Limitation: Maximum Boiling Point Azeotrope}

All mixtures previously examined belong to a class of minimum boiling point azeotropes that prefer lower pressure conditions for ease of separation. This coincides with the phenomena in the UD system where the micro-point vacuum conditions introduced by the cavitation bubbles during sonication generate a lower operating pressure environment. This is, however, contrary to the requirement for the maximum boiling point azeotropic mixtures such as nitric acid/water and acetone/chloroform mixtures that prefer a high pressure operation to shift the azeotropic points downward (Ashokkumar et al., 2007; Modla and Lang, 2008). This is an important limitation of the proposed ultrasonic distillation process.

\section{Comparison of Ultrasonic Distillation with Extractive Distillation}

\section{Extractive Distillation Process}

Extractive Distillation (ED) is a widely applied technology used to separate azeotropes and mixtures with relative volatilities of approximately 1.1 and below (Mahdi et al., 2015a; Hosgor et al., 2014). Because it is a common method used to separate azeotropic mixtures, it is interesting to compare the proposed ultrasonic distillation system to this process. As a case study, a homogeneous extractive distillation process to separate the ETAC/ETOH mixture is investigated and DMSO is selected as the entrainer because it offers a feed ratio of $1: 1$ and the highest relative volatility compared with other candidates as illustrated in Table 3 (Zhang et al., 2012). Similar to the previous case, the feed flow rate is set at $100 \mathrm{kmol} / \mathrm{h}$ of saturated liquid at $25^{\circ} \mathrm{C}$ and NRTL is selected as the thermodynamic model. For the purpose of comparison, feed composition is assumed to be equimolar.
The schematic diagram of the homogeneous extractive distillation process is shown in Figure 10. It is a two-column system, one for extraction and another for solvent recovery. The extraction column has two feed streams, with the entrainer (S) fed at a location higher than the original mixture because it has a higher boiling point. Pure ETAC is collected as the top distillate product of the first Distillation Column (DC1), while the bottom product contains a mixture of DMSO and ETOH is fed to the second Distillation Column (DC2). A high purity ETOH by-product and DMSO are obtained as the top distillate and bottom product of $\mathrm{DC} 2$, respectively. DMSO that is recovered is recycled back to the DC1. Table 4 presents the main design parameters for the extractive distillation process.

Table 3: Extractive distillation agents recommended for separating an ETAC/ETOH mixture

\begin{tabular}{lll}
\hline Entrainers & Ratio & Relative volatility \\
\hline dimethyl sulfoxide (DMSO) & $1: 1$ & 1.859 \\
N,N-dimethylacetamide (DMAC) & $1: 1$ & 1.707 \\
N,N-dimethylformamide (DMF) & $1: 1$ & 1.407 \\
N-methyl-2-pyrrolidone (NMP) & $1: 1$ & 1.341 \\
\hline
\end{tabular}

Table 4: Design parameters of a two-column extractive distillation sequence

\begin{tabular}{llr}
\hline Design parameters & Unit & Value \\
\hline Reflux ratio DC1 & $\mathrm{Kmol} / \mathrm{Kmol}$ & 2 \\
Number of stages DC1 & - & 35 \\
Feed stage of entrainer & - & 5 \\
Feed stage DC1 & - & 24 \\
Reflux ratio DC2 & $\mathrm{Kmol} / \mathrm{Kmol}$ & 1 \\
Number of stages DC2 & - & 27 \\
Feed stage DC2 & - & 15 \\
Feed flowrate of ETAC & $\mathrm{Kmol} / \mathrm{hr}$ & 50 \\
Feed flowrate of ETOH & $\mathrm{Kmol} / \mathrm{hr}$ & 50 \\
Feed flowrate of entrainer & $\mathrm{Kmol} / \mathrm{hr}$ & 100 \\
ETAC recovery & $\mathrm{mol} \%$ & 99 \\
ETOH recovery & $\mathrm{mol} \%$ & 97 \\
\hline
\end{tabular}

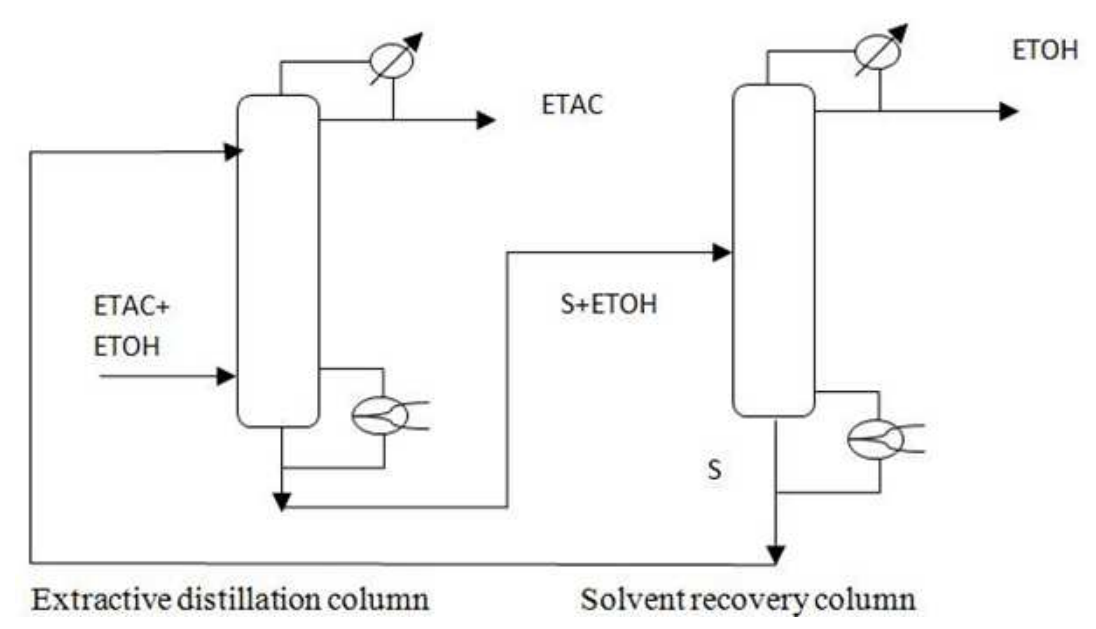

Fig. 10: Schematic diagram of the extractive distillation process, where $S$ is a solvent (entrainer) component 


\section{Comparison of Energy Consumption}

Table 5 presents a comparison of the energy consumption for the two distillation systems. Because the ED is a two-column system, it has two sets of reboilers and condensers. Although the UD has only one reboiler and condenser, it has 15 sonication devices in the rectifying sections and these devices consume electricity as a power source. The net result gives a lower energy requirement in terms of $\mathrm{GJ} /$ hour for the $\mathrm{ED}$ process to produce 99 mole $\%$ of ETAC. The total energy requirements for UD and ED technologies are 28.213 and $21.349 \mathrm{GJ} / \mathrm{hr}$, respectively. However, this comparison does not correspond to the actual costs because the cost per joule of energy for the three energy consumption is not the same $\left(Q_{C}, Q_{B}\right.$ and $\left.Q_{U}\right)$.

\section{Comparison of Operating Cost}

The economic comparison between UD and ED processes will be same system which is ETAC/ETOH mixture and same operation conditions as considered in previous section. The investment cost of equipment for the both processes are not available involves the cost of trays, tower, heat exchangers (reboiler and condenser) and reflux drum, as well as transducer for UD process and also cost of the raw material is fixed. In this study the operating cost of utility was only considered which involves the cost of cooling water, steam and the electric consumption of sonication devices.

The goal of the economic comparison is to minimal separation costs for the processes while satisfying the product purity requirements. The operating cost $\left(C_{E D}\right)$ for the ED process includes the costs of condensers $\left(C_{c}\right)$ and reboilers $\left(C_{r}\right)$ for the two columns, while in the case of the UD process, the operating cost $\left(C_{U D}\right)$ as a result of the ultrasonic transducer $\left(C_{u}\right)$ is added to the costs associated with the condenser and reboiler. These are represented by the following equations:

$$
\begin{aligned}
& C_{E D}=\sum_{1}^{2}\left(C_{c}+C_{r}\right)[\$ / h] \\
& C_{U D}=C_{c}+C_{r}+C_{u}[\$ / h] \\
& C_{c}=W_{c} * Q \\
& C_{r}=S_{r} * Q_{r}
\end{aligned}
$$

$$
C_{u}=E_{u} * Q_{u}
$$

Where:

$Q_{c}(\mathrm{GJ} / \mathrm{h})=$ The heat withdrew from a condenser of a distillation column

$Q_{r}(\mathrm{GJ} / \mathrm{h}) \quad=$ The heat added to a reboiler of a column

$Q_{u}(\mathrm{GJ} / \mathrm{h}) \quad=$ The heat power generated by ultrasound

$W_{c}(\$ / \mathrm{MIb})=$ the cost coefficients of cooling water used in a condenser for a column

$S_{r}(\$ / \mathrm{MIb})=$ The cost coefficients of steam used in a reboiler for a column

$E_{u}(\$ / \mathrm{kWh})=$ The cost of electric consumption of transducers

As a rough comparison, the utility pricing recommended from a chemical engineering design text book (Towler and Sinnott, 2013) is used. Using this cost structure, a low pressure steam of 6 bar and $160^{\circ} \mathrm{C}\left(S_{r}\right)$ needed for the reboiler is available at USD 4.03 per MIb. The cooling water costs include the cost of water at USD 2 per 1000 gal, pumping costs of between 1 and 2 $\mathrm{kWh} / 1000$ gal and a chemical treatment of about USD 0.02 per 1000 gal. Thus, the overall price of cooling water $(S c)$ is estimated to be USD 2.14 per 1000 gal. The electricity cost for the ultrasonic transducer $(\mathrm{Su})$ is fixed at USD 0.06 per $\mathrm{kWh}$.

A detailed summary of the results for operation cost of both processes can be calculated by using Equations 8 to 12 as reported in Table 6 . Note that in case of UD process, the operating cost of the transducers is approximately $22 \%$ of the total cost. Thus the utility cost of the transducers has not a great impact in increasing the operating cost. Since there is no secondary distillation column in the UD process, the operation cost of this process is more economical (savings of around 14.6\%) when compared with the ED process. Using the values recommended in 26 , which may be inaccurate in practice because the costs of utilities vary significantly depending on the plant location, the overall energy costs favor the UD.

Based on the results from Table 5 and 6 , the comparison of the ED and UD does not conclude a distinct advantage for any of the systems in terms of

\begin{tabular}{|c|c|c|c|c|c|c|}
\hline \multirow[b]{2}{*}{ Technique } & \multirow{2}{*}{$\begin{array}{l}\text { Electric } \\
\text { QU }\end{array}$} & \multicolumn{2}{|c|}{ DC1 column } & \multicolumn{2}{|c|}{ DC2 column } & \multirow[b]{2}{*}{$\begin{array}{l}\text { Total } \\
(\mathrm{GJ} / \mathrm{hr})\end{array}$} \\
\hline & & QC & QB & $\mathrm{QC}$ & QB & \\
\hline Ultrasonic Distillation (UD) & 12.657 & 7.53 & 8.0 & - & - & 28.20 \\
\hline Extractive Distillation (ED) & - & 6.26 & 8.8 & 2.7 & 3.6 & 21.35 \\
\hline
\end{tabular}
total energy requirement. However, if the issue was to be examined from overall perspectives, the use of the UD would be more advantageous.

Table 5: Design parameters of a two-column extractive distillation sequence 
Table 6: Operation cost of the configurations of the US process

\begin{tabular}{|c|c|c|c|c|}
\hline \multirow[b]{2}{*}{ Item } & \multicolumn{2}{|l|}{ ED } & \multicolumn{2}{|l|}{ UD } \\
\hline & Operation cost $(\$ / \mathrm{h})$ & Cost Percentage $\%$ & Operation cost $(\$ / \mathrm{h})$ & Cost Percentage $\%$ \\
\hline Condenser of column 1 & 62.5160 & 5.633 & 75.15 & 7.94 \\
\hline Reboiler of column 1 & 724.2429 & 65.258 & 661.70 & 69.81 \\
\hline Condenser of column 2 & 27.0340 & 2.435 & - & - \\
\hline Reboiler of column 2 & 296.0136 & 26.674 & - & - \\
\hline Electricity transducers & - & - & 210.97 & 22.25 \\
\hline Total & 1109.8000 & 100.000 & 947.82 & 100.00 \\
\hline
\end{tabular}

In the $\mathrm{ED}$, the use of entrainers introduces additional occupational hazards and the overall costs associated with maintenance and other costs associated with wastewater treatment and chemical disposal are expected to be higher. In addition, the UD system offers significant space savings and reduction of the capital costs of equipment such as the distillation column, pumps, vessels and heat exchangers because it is a single column system.

\section{Safety Perspectives}

One of the prime objectives of process intensification is to improve safety. It is one of the strategies in inherent safety design concept where reduction of the likelihood of failures is achieved because there is a reduction in the number of equipment components compared to alternatives such as extractive distillation. Intensification also facilitates the process by increasing the separation efficiency, thus resulting in smaller equipment. This can be clearly illustrated when the proposed UD is compared to the ED that is typically used in practice.

Moreover, since an ED process requires an additional chemical to serve as the entrainer, depending on the type of entrainer used, varieties of additional hazards are introduced to the process. For example, the DMSO entrainer used in the above comparison is a clear colorless liquid with a slight sulfurous odor, a specific gravity of 1.1008 and a melting point of $18.45^{\circ} \mathrm{C}$. It is flammable with a flash point between 37.8 and $93.3^{\circ} \mathrm{C}$. This chemical is toxic to blood, kidneys, liver, mucous membranes, skin and eyes. Its teratogenicity is not conclusive and therefore, it is not classified as such. DMSO is also easily absorbed through skin with the chronic effect of scaling dermatitis. Exposure to a high vapor concentration may include coughing, headache and shortness of breath.

This simplified hazard identification provides a clear advantage of not having DMSO as part of the process. However, it is an effective entrainer needed in the ED process. The proposed UD is thus more advantageous in terms of safety and health perspectives, with further opportunities to be improved to enhance economic savings with more detailed studies on the use of ultrasonic transducers, both in terms of sizing as well as installation location.

\section{Conclusion}

This work has successfully illustrated the potential of sonication phenomena in enhancing the separation process involving azeotropic mixtures. The proposed ultrasonic distillation column has successfully achieved the targeted $99 \mathrm{~mol} \%$ overhead products for various azeotropic mixtures. This preliminary study on the separation of an ETAC/ETOH mixture has shown the benefits of the proposed system in terms of process economy as well safety perspectives. However, the proposed process is limited only to minimum boiling point azeotropic mixtures. It has nevertheless set a good beginning toward further development of the ultrasonic distillation system.

\section{Acknowledgment}

The author is grateful to the University of Babylon. The contribution of the Ministry of Oil, Iraq in providing scholarships for the study is acknowledged.

\section{Author's Contributions}

Taha Mahdi: Idea, design, writing the manuscript, simulation and mathematical model. Participated in writing the revising the paper.

Ammar Emad Al-Kawaz: Participated in the idea and writing the revising the paper.

\section{Ethics}

This article is original. Author declare that are not ethical issues that may arise after the publication of this manuscript.

\section{References}

Alkhudhiri, A., N. Darwish and N. Hilal, 2012. Membrane distillation: A comprehensive review. Desalination, 287: 2-18.

DOI: $10.1016 /$ j.desal.2011.08.027

Apfel, R.E., 1997. Sonic effervescence: A tutorial on acoustic cavitation. J. Acoust. Society Am., 101: 1227-1237. DOI: $10.1121 / 1.418130$ 
Ashokkumar, M., J. Lee, S. Kentish and F. Grieser, 2007. Bubbles in an acoustic field: An overview. Ultras. Sonochem., 14: 470-475.

DOI: 10.1016/j.ultsonch.2006.09.016

Ashokkumar, M. and T.J. Mason, 2007. Sonochemistry. Kirk-othmer encyclopedia of chemical technology.

Bono, A., R. Sarbatly, D. Krishnaiah, P.M. San and F.Y. Yan, 2008. Effect of ultrasound on liquid phase adsorption of azeotropic and non-azeotropic mixture. Catal. Tod., 131: 472-476. DOI: 10.1016/j.cattod.2007.10.084

Chang, H., S.H. Cheng, H.C. Chiang, Y.H. Chen and Y.Y. Chang, 2012. Simulation study of an integrated methanol micro fuel processor and fuel cell system. Chem. Eng. Sci., 74: 27-37.

DOI: $10.1016 /$ j.ces.2012.01.043

Chen, G., R. Shan, J. Shi and B. Yan, 2014. Ultrasonicassisted production of biodiesel from transesterification of palm oil over ostrich eggshellderived $\mathrm{CaO}$ catalysts. Bioresource Technol., 171: 428-432. DOI: 10.1016/j.biortech.2014.08.102

Choudhury, H.A., S. Chakma and V.S. Moholkar, 2014. Mechanistic insight into sonochemical biodiesel synthesis using heterogeneous base catalyst. Ultras. Sonochem., 21: 169-181.

DOI: 10.1016/j.ultsonch.2013.04.010

Hosgor, E., T. Kucuk, I.N. Oksal and D.B. Kaymak, 2014. Design and control of distillation processes for methanol-chloroform separation. Comput. Chem. Eng., 67: 166-177.

DOI: 10.1016/j.compchemeng.2014.03.026

Kamihara, Y., T. Watanabe, M. Hirano and H. Hosono, 2008. Iron-based layered superconductor $\mathrm{La}\left[\mathrm{O}_{1-\mathrm{x}}\right.$ $\mathrm{F}_{\mathrm{x}}$ ] FeAs $(\mathrm{x}=0.05-0.12)$ with $\mathrm{T}_{\mathrm{c}}=26 \mathrm{~K}$. J. Am. Chem. Society, 130: 3296-3297.

DOI: $10.1021 / \mathrm{ja} 800073 \mathrm{~m}$

Katikaneni, S.P.R. and M. Cheryan, 2002. Purification of fermentation-derived acetic acid by liquid-liquid extraction and esterification. Indus. Eng. Chem. Res., 41: 2745-2752. DOI: 10.1021/ie010825x

Kirpalani, D. and F. Toll, 2002. Revealing the physicochemical mechanism for ultrasonic separation of alcohol-water mixtures. J. Chem. Phys., 117: 3874-3877. DOI: 10.1063/1.1495849

Liang, S., Y. Cao, X. Liu, X. Li and Y. Zhao et al., 2017. Insight into pressure-swing distillation from azeotropic phenomenon to dynamic control. Chem. Eng. Res. Design, 117: 318-35.

DOI: $10.1016 /$ j.cherd.2016.10.040

Louisnard, O. and J. González-García, 2011. Acoustic Cavitation. In: Ultrasound Technologies for Food and Bioprocessing, Feng, H., G. Barbosa-Canovas and J. Weiss (Eds.), Springer, New York, pp: 13-64.

Mahdi, T., A. Ahmad, A. Ripin and M.M. Nasef, 2015a. State-of-the-art technologies for separation of azeotropic mixtures. Sep. Purif. Rev., 44: 308-330. DOI: $10.1080 / 15422119.2014 .963607$
Mahdi, T., A. Ahmad, A. Ripin, T.A.T. Abdullah and M.M. Nasef et al., 2015b. Mathematical modeling of a single stage ultrasonically assisted distillation process. Ultras. Sonoch., 24: 184-192. DOI: $10.1016 /$ j.ultsonch.2014.11.005

Mahdi, T., A. Ahmad, A. Ripin and M.M. Nasef, 2014. Vapor-liquid equilibrium of ethanol/ethyl acetate mixture in ultrasonic intensified environment. Korean J. Chem. Eng., 31: 875-880. DOI: $10.1007 / \mathrm{s} 11814-014-0011-9$

Merouan, S., O. Hamdaoui, Y. Rezgui and M. Guemini, 2013. Effects of ultrasound frequency and acoustic amplitude on the size of sonochemically active bubbles-Theoretical study. Ultras. Sonoch., 20: 815-819. DOI: 10.1016/j.ultsonch.2012.10.015

Modla, G. and P. Lang, 2008. Feasibility of new pressure swing batch distillation methods. Chem. Eng. Sci., 63: 2856-2874. DOI: 10.1016/j.ces.2008.02.034

Nii, S., K. Matsuura, T. Fukazu, M. Toki and M. Kawaizumi, 2006. A novel method to separate organic compounds through ultrasonic atomization. Chem. Eng. Res. Design, 84: 412-415. DOI: $10.1205 /$ cherd05016

Parkar, P.A., H.A. Choudhary and V.S. Moholkar, 2012. Mechanistic and kinetic investigations in ultrasound assisted acid catalyzed biodiesel synthesis. Chem. Eng. J., 187: 248-260.

DOI: 10.1016/j.cej.2012.01.074

Ripin, A., S.K. Abdul Mudalip, Z. Sukaimi, R.M. Yunus and Z.A. Manan, 2009. Effects of ultrasonic waves on vapor-liquid equilibrium of an azeotropic mixture. Sep. Sci. Technol., 44: 2707-2719. DOI: 10.1080/01496390903014474

Sulaiman, A.Z., A. Ajit, R.M. Yunus and Y. Chisti, 2011. Ultrasound-assisted fermentation enhances bioethanol productivity. Biochem. Eng. J., 54: 141-150. DOI: 10.1016/j.bej.2011.01.006

Suzuki, K., K. Arashi and S. Nii, 2012. Determination of droplet and vapor ratio of ultrasonically-atomized aqueous ethanol solution. J. Chem. Eng. Jpn., 45: 337-342. DOI: 10.1252/jcej.11we196

Towler, G.P. and R.K. Sinnott, 2013. Chemical Engineering Design: Principles, Practice and Economics of Plant and Process Design. 2nd Edn., Elsevier, ISBN-10: 0080966608, pp: 1320.

Wisniak, J., L. Aharon, Y. Nagar, H. Segura and R. Reich, 2001. Effect of pressure on the vapor-liquid equilibria of the system methanol + ethyl 1,1dimethylethyl ether. Phys. Chem. Liq., 39: 723-737. DOI: 10.1080/00319100108031688

Zhang, Z.G., M. Lv, L.F. Chen and W.X. Li, 2012. Organic solvents for separating ethyl acetateethanol by extractive distillation. Adv. Mater. Res., 550-553: 699-703.

DOI: 10.4028/www.scientific.net/AMR.550-553.699 